\title{
Comparison of 16S rDNA and 16S/23S Intergenic Region Sequences Among Citrus Greening Organisms in Asia
}

\author{
Siti Subandiyah, Department of Entomology and Plant Pathology, Faculty of Agriculture, Gadjah Mada University, \\ Yogyakarta 55281, Indonesia; Toru Iwanami, Senior Research Scientist, Yoshiko Kondo, Masaki Kobayashi Re- \\ search Technicians, National Institute of Fruit Tree Science, Fujimoto 2-1, Tsukuba, Ibaraki 305-8605 Japan; Shinji \\ Tsuyumu, Professor, Faculty of Agriculture, Shizuoka University, Shizuoka 422, Japan; and Hiroyuki Ieki, Chief, \\ National Institute of Fruit Tree Science, Fujimoto 2-1, Tsukuba, Ibaraki 305-8605, Japan
}

\begin{abstract}
Subandiyah, S., Iwanami, T., Tsuyumu, S., and Ieki, H. 2000. Comparison of 16S rDNA and $16 \mathrm{~S} / 23 \mathrm{~S}$ intergenic region sequences among citrus greening organisms in Asia. Plant Dis. 84:1518.

Polymerase chain reaction was used to amplify and sequence the 16S ribosomal RNA gene (rDNA) and $16 \mathrm{~S} / 23 \mathrm{~S}$ intergenic region of several isolates of citrus greening organism (GO) from Japan, the Philippines, Indonesia, and Thailand. The sequences of $16 \mathrm{~S}$ rDNA were identical among all the isolates studied, very similar to the published sequences of Thai ( 99.4 to $100 \%$ identity), Nepalese (100\% identity), and Indian ( $98.8 \%$ identity) strains, and less similar to an African strain (97.5\% identity). The sequences of the intergenic region between $16 \mathrm{~S}$ and $23 \mathrm{~S}$ rDNA were also identical among the isolates examined as well as the reported Nepalese and Thai isolates. They were close to the sequences of reported strains of India and China (99.2\%) and apart from those of the African strain (85.5\%). These results suggested that some isolates of GO from Japan, the Philippines, Indonesia, Thailand, and Nepal constitute one strain, which is similar to Indian and Chinese strains and distinct from the African strain.
\end{abstract}

Citrus greening is one of the most serious diseases of citrus in many parts of Asia and Africa (3). It is caused by a non-culturable, phloem-restricted Gram-negative bacteria $(5,6)$. Asian and African citrus greening organisms (GOs) are transmitted by different insect vectors, Diaphorina citri (10) and Trioza erytreae (11), respectively. The Asian strain of GO produces severe symptoms both under cool (22 to $\left.24^{\circ} \mathrm{C}\right)$ and warm $\left(27\right.$ to $\left.30^{\circ} \mathrm{C}\right)$ temperatures, while the African strain induces

Corresponding author: T. Iwanami

E-mail: tiwanami@sta.go.jp

Contribution 1148 of National Institute of Fruit Tree Science.

The nucleotide sequence data reported in this paper will appear in the DDBJ, EMBL, and GenBank nucleotide sequence databases with the accession number AB008366 and AB019793.

This work was partly supported by a dissertation Ph.D. program from the Japan Society for the Promotion of Science. The field survey was conducted in collaboration with Naha Plant Protection Station and Okinawa Prefectural Agriculture Research Station.

Accepted for publication 3 September 1999.

Publication no. D-1999-1028-01R

(C) 2000 The American Phytopathological Society severe symptoms only under cool conditions (2).

The comparison of $16 \mathrm{~S}$ ribosomal DNA (16S rDNA) is a useful tool for deducing phylogenetic and evolutionary relationships among bacteria and other prokaryotes (20). 16S rDNA of an Asian (Poona strain, India) and an African (Nelspruit strain, South Africa) GO have been amplified by polymerase chain reaction (PCR), cloned, and sequenced (7). The nucleotide sequence identity between Poona (Indian) and Nelspruit (African) strains was $97.7 \%$. The two strains were placed in the $\alpha$-subdivision of Proteobacteria based on comparison with the sequences of other bacteria. The designations "Candidatus Liberobacter asiaticum" and "Candidatus Liberobactor africanum" were given to the Asian and African GOs (9), respectively, according to the rules established for uncultured organisms (15).

In Asia, the GO and its insect vector, $D$. citri, are widely distributed from Pakistan to Taiwan. Recently, some Thai and Nepalese isolates of GO were molecularly and biologically characterized (16-18). In Japan, D. citri is common in the southern islands, including Iriomote and Okinawa (13), and GO was found recently on Iriomote Island (12). The spread of greening on this island is not a great threat because there are very few citrus species commer- cially cultivated in this island (12). There have been no additional reports on the occurrence of citrus greening in other parts of Japan. We surveyed the presence of greening on Okinawa Island, which is about $500 \mathrm{~km}$ northwest of Iriomote Island. The outbreak of greening on this island had been greatly feared because this island is one of the major citrus-producing areas in Japan.

The objectives of this study were detection and molecular characterization of GOs on Okinawa Island to assess the relationship to other Asian and African GO strains. Identification of GOs was attempted by graft-transmission to indicator plants using samples from suspected trees. The $16 \mathrm{~S}$ rDNA and $16 \mathrm{~S} / 23 \mathrm{~S}$ intergenic spacer regions of GOs were amplified and sequenced to supplement the biological indexing results. The sequence was compared with those of other Asian and African strains of GO.

\section{MATERIALS AND METHODS}

Sample collection and graft transmission to indicator plants. Survey trips were made to Okinawa Island in September and October 1994. Buds were collected from trees with greening-type symptoms. Shoots were side-grafted to indicator plants (19) that consisted of a rough lemon seedling top-worked with a bud of cv. Orlando tangelo (Citrus reticulata $\times$ C. paradisi). GO isolate OK901 from Iriomote Island (12), provided by T. Miyakawa (South Kyushu University), was used as a positive control. Two plants were inoculated from each source and maintained separately at $25 / 20^{\circ} \mathrm{C}$ and $30 / 25^{\circ} \mathrm{C}$ (day/night) after initial incubation at $25 / 20^{\circ} \mathrm{C}$ for 3 weeks. A Philippine isolate was obtained from the quarantine facility of the Yokohama Plant Quarantine Station, a Thai isolate NP (16) was obtained from K. Nakashima (Japan International Research Center of Agricultural Sciences), and two Indonesian isolates were collected from separate locations and introduced to Japan by S. Subandiyah under quarantine office permission. These foreign citrus greening isolates were used for PCR and sequencing experiments. 
DNA extraction and PCR. DNA was extracted from leaf midribs and bark of the cv. Orlando tangelo indicator plant by a cetyltrimethylammoniumbromide procedure (14) 6 months after grafting. DNA from $500 \mathrm{mg}$ of tissue was dissolved in $200 \mu \mathrm{l}$ of $10 \mathrm{mM}$ Tris-HCl, $\mathrm{pH} 8.0,1 \mathrm{mM}$

Table 1. Primer sequences for polymerase chain reaction (PCR) and sequencing of 16S rDNA and the $16 \mathrm{~S} / 23 \mathrm{~S}$ intergenic regions of the citrus greening organism

\begin{tabular}{llc}
\hline Primers & \multicolumn{1}{c}{ Nucleotide sequences $\left(\mathbf{5}^{\prime} \mathbf{3}^{\prime}\right.$ ) } & Nucleotide positions \\
\hline 16S rDNA & & \\
PCR primers & & \\
OI1 & GCGCGTATGCAATACGAGCGGCA & $39-61^{\mathrm{a}}$ \\
OI2c & GCCTCGCGACTTCGCAACCCAT & $1,183-1,204$ \\
Sequencing primers & & \\
16S-fwd-1 & GACGGGTGAGTAACGCGTAGGA & $62-83$ \\
16S-fwd-2 & AGGCGGCGATTAAGTTAGAG & $501-520$ \\
16S-fwd-3 & GCACAAGCGTGGAGCATGTGGT & $849-870$ \\
16S-rev-1 & GGGCTTCTTCTCCGATACCGTC & $421-399$ \\
16S-rev-2 & ACAGCTAGCACTCATCGTTT & $750-731$ \\
16S-rev-3 & TGTAGCACGTGTGTAGCCCAGC & $1,170-1,149$ \\
16S/23S intergenic region & & \\
PCR primers & & $1,204-1,183$ \\
OI2 & ATGGGTTGCGAAGTCGCGAGGC & \\
23S1-revb & CGCCCTTCTCTCGCGCTTGA & $1,214-1,233$ \\
Sequencing primers & CCCCAAAAGCCATCTCAGTT & $1,421-1,440$ \\
16S-fwd-4 & GAAGTCGTAACAAGGTAGCC & $313-332^{\mathrm{c}}$ \\
16S-fwd-5 & TCTAACCACCTGAGCTACGG & $210-191$ \\
Spc-fwd-1 & TCTAACCACCTGAGCTACGG & $456-436$ \\
Spc-rev-1 & TGTCGCATACAATGCCAACAT & \\
Spc-rev-2 & CGCCCTTCTCTCGCGCTTGA & \\
23S1-rev &
\end{tabular}

a The nucleotide positions are numbered following the sequences in the EMBL databases L22532 (7) and U61359 (9) for 16S rDNA and 16S/23S intergenic spacer region, respectively.

b The primer reported by Jagoueix et al. (9).

${ }^{c}$ The nucleotide positions are numbered following the sequences in the EMBL databases L22532 (7) and U61359 (9) for 16S rDNA and 16S/23S intergenic spacer region, respectively.

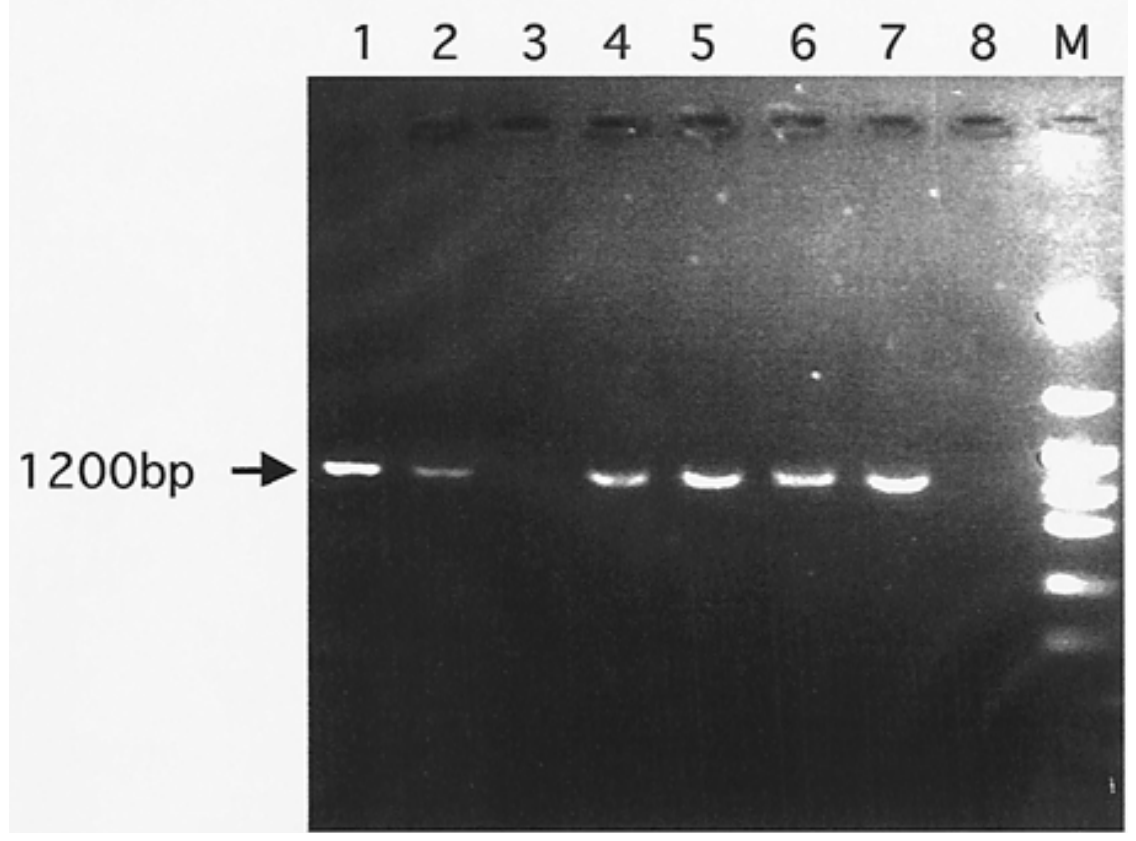

Fig 1. Agarose gel electrophoresis of DNAs amplified with primers OI1 and OI2c from leaf-tissue extracts. Lanes 1 and 2, from plants infested with greening from Okinawa (KIN1 and OKS7); lane 3, from plant from Okinawa (without greening); lane 4, from plant infested with greening from Iriomote (OK901); lane 5, from plant infested with greening from the Philippines (Phi-1); lane 6, from plant infested with greening from Indonesia (IS-1); lane 7, from plant infested with greening from Thailand (NP); lane 8, from healthy cv. Orlando tangelo; lane M, pHY molecular Marker (Yakult Pharmacy). was done using the primers of OI1 and OI2c (Table $1 ; 7)$, whereas the amplification of the spacer intergenic region between $16 \mathrm{~S}$ and $23 \mathrm{~S}$ rDNA was done using the forward primer of OI2 and reverse primer of 23S1 (Table 1; 9). The PCR was carried out first by incubation at $92^{\circ} \mathrm{C}$ for $30 \mathrm{~s}$, followed by 40 cycles of $92^{\circ} \mathrm{C}$ for $60 \mathrm{~s}, 53^{\circ} \mathrm{C}$ for $30 \mathrm{~s}, 72^{\circ} \mathrm{C}$ for $60 \mathrm{~s}$, and a final extension of $10 \mathrm{~min}$ at $72^{\circ} \mathrm{C}$. The amplified DNA was analyzed on a $1.5 \%$ agarose gel and stained with ethidium bromide before and after incubation with restriction enzyme $X b a \mathrm{I}$.

DNA sequencing and data analysis. The PCR product was adjusted to 10 to 30 $\mathrm{ng} / \mu \mathrm{l}$ after purification using the NucleotraP-CR Extraction kit (Macherey-Nagel, Düren, Germany). Direct sequencing was performed on the DNA using ABI Prism Dye Terminator Cycle Sequencing Ready Reaction kit (PE Applied Biosystems, Foster City, CA). The primers were used for sequencing the amplified fragments of the $16 \mathrm{~S} \mathrm{rDNA}$ and the intergenic region between $16 \mathrm{~S}$ and $23 \mathrm{~S}$ rDNA (Table 1).

The sequences were determined by an automated sequencer (PE Applied Biosystems, model 373S) and analyzed using GENETYX software (Software Development, Tokyo). The sequences were compared and aligned with those of $16 \mathrm{~S}$ rDNA and the $16 \mathrm{~S} / 23 \mathrm{~S}$ intergenic region obtained from the DNA Database of Japan, EMBL, and Genbank data bases.

\section{RESULTS}

Graft transmission tests. Out of 27 isolates from Okinawa Island, 4 isolates and the positive control OK901 induced severe vein yellowing and leaf mottle on the emerging shoots of cv. Orlando tangelo within 12 weeks after grafting. The symptoms appeared prominently at both $25 / 20^{\circ} \mathrm{C}$ and $30 / 25^{\circ} \mathrm{C}$ (day/night).

Amplification of $16 \mathrm{~S}$ rDNA and the $16 \mathrm{~S} / 23 \mathrm{~S}$ intergenic spacer region from GO-infected plant extracts. PCR using primers of OI1 and OI2c produced an amplified fragment of about 1,200 base pairs (bp) from the cv. Orlando tangelo, which had been inoculated with one of the isolates OK 901, KIN1, OKS7, OKS13, and OKS14, and showed the typical symptoms (Fig. 1). The amplification of the intergenic region between $16 \mathrm{~S}$ and $23 \mathrm{~S}$ rDNA resulted in fragment of about $900 \mathrm{bp}$ (Fig. 2). Fragments of the same sizes were also amplified from one isolate from the Philippines (Phi-1), two isolates from Indonesia (IS-1, IS-2), and one isolate from Thailand (NP). However, these fragments were not amplified from the two non-inoculated cv. Orlando tangelo (healthy control) plants and the 23 plants which did not develop greening symptoms after grafting. The amplified DNA fragments of the 16S rDNA of GOs from Japan, the Philippines, Indonesia, and Thailand were digested by $\mathrm{XbaI}$ into two fragments of 650 and $550 \mathrm{bp}$ 
(Fig. 3), as reported only for Asian GOs but not for the African GO (8).

Sequences of $16 \mathrm{~S}$ rDNA and the 16S/23S intergenic spacer region. The amplified fragments of 16S rDNA and the $16 \mathrm{~S} / 23 \mathrm{~S}$ intergenic spacer region were directly sequenced in both orientations using primers listed in Table 1 . The determined sequence was $1,137 \mathrm{bp}$ long for the fragment amplified from 16S rDNA and $893 \mathrm{bp}$ for the fragment from the $16 \mathrm{~S} / 23 \mathrm{~S}$ intergenic spacer region. The combined sequence of these regions was $2,027 \mathrm{bp}$ long. The sequences of these regions were identical among four isolates (KIN1, OKS7, OKS13, and OKS14) from Okinawa Island, one from Iriomote Island (OK901), two from Indonesia (IS-1 and IS-2), one from Thailand (NP), and one from the Philippines (Phi-1). These sequences are very similar to the reported sequences of $16 \mathrm{~S}$ rDNA of the Thai (99.4 to $100 \% ; 16,17)$, Nepalese $(100 \% ; 16)$, and Indian $(98.8 \%$; 7) strains, and less similar to that of the African strain $(97.5 \%$; 7). The sequences of the $16 \mathrm{~S} / 23 \mathrm{~S}$ intergenic spacer region were identical among the isolates used in this study, as well as the Thai and Nepalese isolates reported previously (18). These sequences showed $99.2 \%$ identity with the Indian and Chinese strains and $85.5 \%$ identity with African strain. The sequence differences in $16 \mathrm{~S}$ rDNA and the $16 \mathrm{~S} / 23 \mathrm{~S}$ intergenic region between the GO isolate of Japan (KIN1) and that of India (Poona) are presented in Tables 2 and 3.

\section{DISCUSSION}

In Japan, citrus greening was confirmed only once on the citrus plants in the southernmost small island of Iriomote. Our study clearly demonstrated the occurrence of citrus greening at four locations on Okinawa Island, which is located about 550 $\mathrm{km}$ northwest of Iriomote Island. Citrus greening will become an epidemic on Okinawa Island because the insect vector $D$. citri is common to this area. Economic outcomes are potentially serious, because Okinawa Island is one of the major citrusproducing areas of Japan. It is probable that there are some false negative results of the biological indexing because GO is not very easily graft transmissible (19).

GOs in Japan (Iriomote and Okinawa Islands) were considered to be Asian type rather than African type, based on the tolerance to high temperature and cleavage pattern with the restriction enzyme $X b a \mathrm{I}$ of the PCR fragment of $16 \mathrm{~S}$ rDNA. The sequences of the amplified 16S rDNA and the intergenic region between $16 \mathrm{~S}$ and $23 \mathrm{~S}$ rDNA were identical among five isolates from Japan, (OK901, KIN1, OKS7, OKS13, and OKS14), one from the Philippines (Phi-1), two from Indonesia (IS-1 and IS-2), and one from Thailand (NP). These sequences are very similar to the reported sequences of $16 \mathrm{~S}$ rDNA and the

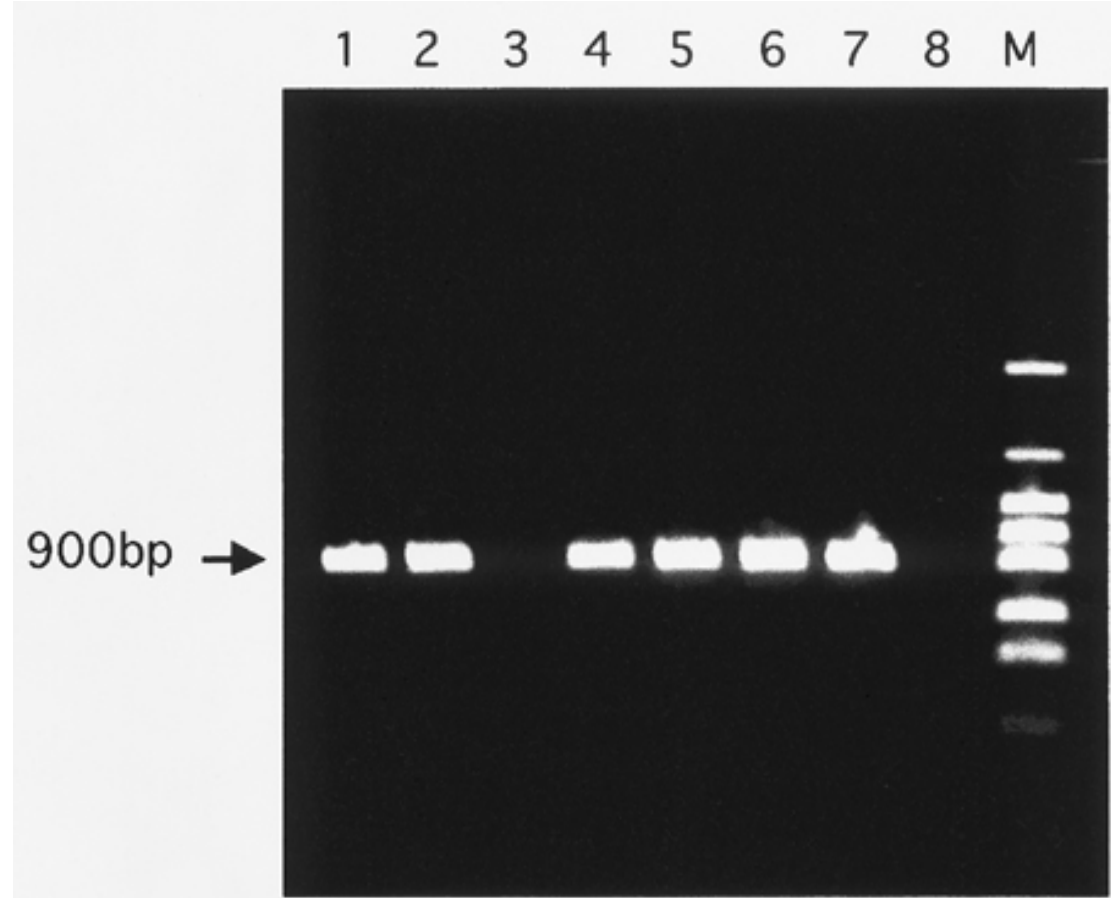

Fig. 2. Agarose gel electrophoresis of DNAs amplified with primers OI2c and $23 \mathrm{~S} 1$ from leaf-tissue extracts. Lanes 1 and 2, from plants infested with greening from Okinawa (KIN1 and OKS7); lane 3, from plants from Okinawa (without greening); lane 4, from plants infested with greening from Iriomote (OK901); lane 5, from plants infested with greening from the Philippines (Phi-1); lane 6, from plant infested with greening from Indonesia (IS-1); lane 7, from plant infested with greening from Thailand (NP); lane 8, from healthy cv. Orlando tangelo; lane M, pHY molecular Marker (Yakult Pharmacy).

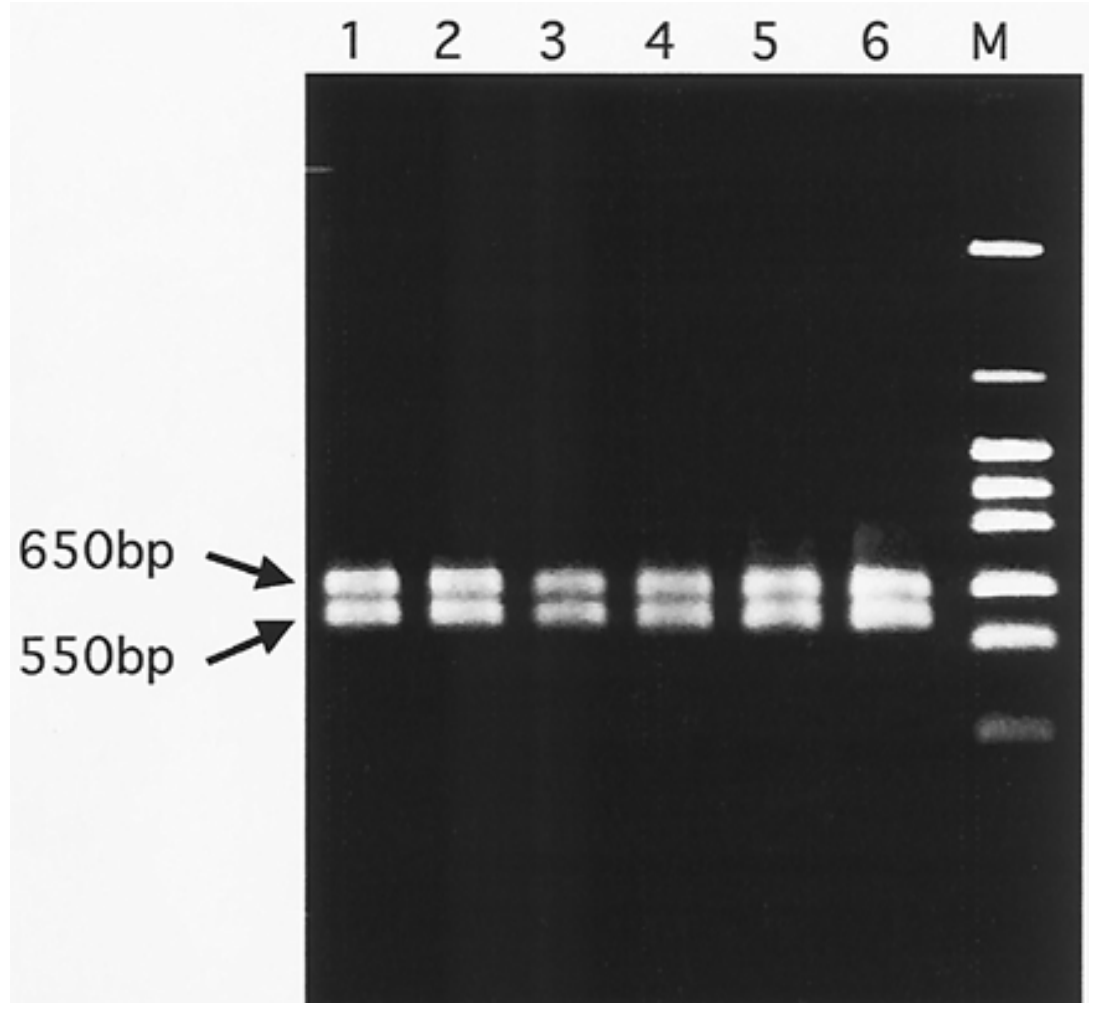

Fig. 3. Agarose gel electrophoresis of DNAs amplified with primers OI1 and OI2c from leaf-tissue extracts after digestion with restriction enzyme XbaI. Lanes 1 and 2, from plants infested with greening from Okinawa (KIN1 and OKS7); lane 3, from plants infested with greening from Iriomote (OK901); lane 4, from plants infested with greening from the Philippines (Phi-1); lane 5, from plant infested with greening from Indonesia (IS-1); lane 6, from plant infested with greening from Thailand (NP); lane M, pHY molecular Marker (Yakult Pharmacy). 
Table 2. 16S rDNA sequence difference between the Japanese (KIN1) and Indian (Poona) isolates of the citrus greening organism

\begin{tabular}{|c|c|c|c|c|c|c|c|c|c|c|c|c|c|c|c|c|c|c|}
\hline \multirow[b]{2}{*}{ Isolate } & \multicolumn{18}{|c|}{ Nucleotide positions $^{\mathrm{a}}$} \\
\hline & 98 & 99 & $504-505$ & $531-532$ & 573 & 774 & 777 & 778 & 797 & $856-857$ & 977 & 1124 & 1139 & 1140 & 1298 & 1299 & 1374 & 1375 \\
\hline KIN1 & - & A & $\mathrm{G}$ & $\mathrm{G}$ & - & $\mathrm{G}$ & $\mathrm{G}$ & $\mathrm{C}$ & $\mathrm{G}$ & $\mathrm{G}$ & $\mathrm{T}$ & $\mathrm{C}$ & $\mathrm{G}$ & $\mathrm{C}$ & $\mathrm{C}$ & $\mathrm{G}$ & G & $\mathrm{C}$ \\
\hline Poona & A & $\mathrm{N}$ & - & - & $\mathrm{C}$ & $\mathrm{N}$ & $\mathrm{C}$ & $\mathrm{G}$ & $\mathrm{N}$ & - & $\mathrm{N}$ & $\mathrm{N}$ & $\mathrm{C}$ & $\mathrm{G}$ & $\mathrm{N}$ & $\mathrm{N}$ & - & $\mathrm{N}$ \\
\hline
\end{tabular}

a Nucleotide positions are numbered following the sequence of the 16S rDNA of the citrus greening organism, L22532 (7) in the EMBL databases.

Table 3. $16 \mathrm{~S} / 23 \mathrm{~S}$ intergenic spacer region sequence difference between the Japanese (KIN1) and Indian (Poona) isolates of the citrus greening organism

\begin{tabular}{lccccc}
\hline & \multicolumn{5}{c}{ Nucleotide positions $^{\mathbf{a}}$} \\
\cline { 2 - 6 } Isolate & $\mathbf{2 1 5 - 2 1 6}$ & $\mathbf{2 2 4 - 2 2 5}$ & $\mathbf{3 1 4 - 3 1 5}$ & $\mathbf{3 3 3}$ & $\mathbf{5 2 9 - 5 3 0}$ \\
\hline KIN1 & $\mathrm{C}$ & $\mathrm{G}$ & $\mathrm{G}$ & - & $\mathrm{G}$ \\
Poona & - & - & - & $\mathrm{C}$ & - \\
\hline
\end{tabular}

${ }^{a}$ The nucleotide positions are numbered following the sequence of the $16 \mathrm{~S} / 23 \mathrm{~S}$ intergenic spacer region of the citrus greening organism, U61359 (9) in the EMBL databases.

$16 \mathrm{~S} / 23 \mathrm{~S}$ intergenic region of Thai, Nepalese (16-18), Chinese, and Indian $(7,9)$ isolates, and distinct from the African strain (9). The sequences of the $16 \mathrm{~S}$ rRNA and the intergenic region between $16 \mathrm{~S}$ rRNA and 23S rRNA have been considered to be variable among the strains within the species $(1,7,9,20)$. Jagoueix et al. (9) reported that the strains of India (Poona) and China had sequences identical to the $16 \mathrm{~S} / 23 \mathrm{~S}$ intergenic spacer region, although they belong to different serotype groups (4). Their results suggested that the $16 \mathrm{~S} / 23 \mathrm{~S}$ intergenic spacer region is conserved among Asian GOs. This study showed that sequences of the $16 \mathrm{~S} / 23 \mathrm{~S}$ intergenic spacer of Japanese, Philippine, Indonesian, Thai, and Nepalese isolates are identical, but are slightly different from those of Indian and Chinese isolates, and far different from African isolates. The sequences of $16 \mathrm{~S}$ rDNA were also identical among all Pacific-area isolates used in this investigation, as well as some Thai and Nepalese isolates, but different from those of Indian and African strains. These results suggested that some isolates of GO from Japan, the Philippines, Indonesia, Thailand, and Nepal constitute one strain, which is similar to Indian and Chinese strains and distinct from the African strain, on the basis of the difference in the $16 \mathrm{~S}$ rDNA and the $16 \mathrm{~S} / 23 \mathrm{~S}$ intergenic spacer region sequences.

\section{ACKNOWLEDGMENTS}

We thank A. Mizuno and A. Kawai of Yokohama Plant Protection Station for providing the
Philippine isolate of greening organism; and S. M. Garnsey of the United States Department of Agriculture, Florida, for critical reading of the manuscript.

\section{LITERATURE CITED}

1. Barry, T., Colleran, G., Glennon, M., Dunican, L. K., and Gannon, F. 1991. The $16 \mathrm{~S} / 23 \mathrm{~S}$ ribosomal spacer region as a target for DNA probes to identify eubacteria. PCR Methods Appl. 1:51-56

2. Bové, J. M., Calavan, E. C., Capoor, S. P., Cortez, R. E., and Schwarz, R. E. 1974. Influence of temperature on symptoms of California stubborn, South Africa greening, India citrus decline and Philippine leaf mottling disease. Pages 12-15 in: Proc. 10th. Conf. Int. Organ. Citrus Virol. (IOCV), Riverside, CA.

3. da Graça, J. V. 1991. Citrus greening disease. Annu. Rev. Phytopathol. 29:109-136.

4. Gao, S. J., Garnier, M., and Bové, J. M. 1993. Production of monoclonal antibodies recognizing most Asian strains of the greening BLO by in vitro immunization with an antigenic protein purified from the BLO. Pages 244-249 in: Proc. 12th. Conf. Int. Organ. Citrus Virol. (IOCV), Riverside, CA.

5. Garnier, M., and Bové, J. M. 1983. Transmission of the organism associated with citrus greening disease from sweet orange to periwinkle by dodder. Phytopathology 73:13581363.

6. Garnier, M., Danel, N., and Bové, J. M. 1984. The greening organism is a gram negative bacterium. Pages 115-124 in: Proc. 9th. Conf. Int. Organ. Citrus Virol. (IOCV), Riverside, CA.

7. Jagoueix, S., Bové, J. M., and Garnier M. 1994. The Phloem-limited bacterium of greening disease of citrus is a member of the $\alpha$-subdivision of the Proteobacteria. Int. J. Syst. Bacteriol. 44:379-386.

8. Jagoueix, S., Bové, J. M., and Garnier M. 1995. Techniques for the specific detection of the greening liberobacter species: DNA-DNA hybridization and DNA amplification by PCR. Page 101 in: Abstr. 13th Conf. Int. Organ. Citrus Virol. Fuzhou, China.

9. Jagoueix, S., Bové, J. M., and Garnier, M. 1997. Comparison of the $16 \mathrm{~S} / 23 \mathrm{~S}$ ribosomal intergenic regions of "Candidatus Liberobacter asiaticum" and "Candidatus Liberobacter africanum," the two species associated with citrus Huanglongbing (greening) disease. Int. J. Syst. Bacteriol. 47:224-227.

10. Martinez, A. L., and Wallace, J. M. 1967. Citrus leaf mottle-yellows disease in the Philippines and transmission of the causal virus by a psyllid, Diaphorina citri. Plant Dis. Rep. 51:692-695.

11. Mclean, A. P. D., and Oberholzer, P. C. J. 1965. Citrus psylla, a vector of the greening disease of sweet orange. S. Afr. J. Agric. Sci. 8:297-298.

12. Miyakawa, T., and Tsuno, K. 1989. Occurrence of citrus greening in the southern islands of Japan. Ann. Phytopathol. Soc. Jpn. 66:667-670.

13. Miyatake, Y. 1965. Notes on Psyllidae from the Ryukyu Islands. Kontyu 33:171-189.

14. Murray, M. G., and Thompson, W. F. 1980. Rapid isolation of high molecular weight plant DNA. Nucleic Acids Res. 8:43214325 .

15. Murray, R. G. E., and Schleifer, K. H. 1994. Taxonomic notes: a proposal for recording the properties of putative taxa of procaryotes. Int. J. Syst. Bacteriol. 44:174-176.

16. Nakashima, K., Ohtsu, Y., and Prommintara, M. 1998. Detection of citrus greening in citrus plants and Psylla Diaphorina citri in Thailand. Ann. Phytopathol. Soc. Jpn. 64:153-159.

17. Nakashima, K., Prommintara, M., Ohtsu, Y., Kano, T., Imada J., and Koizumi, M. 1996. Detection of 16S rDNA of Thai isolates of bacterium-like organisms associated with greening disease of citrus. JIRCAS J. 3:1-8.

18. Ohtsu, Y., Nakashima, K., Prommintara, M., and Tomiyasu, Y. 1998. Typical symptoms of citrus greening on mandarin trees in Nepal, supported by detection and characterization of ribosomal DNA of the causal organisms. Ann. Phytopathol. Soc. Jpn. 64:539-545.

19. Roistacher, C. N. 1991. Graft-transmissible diseases of citrus. Handbook for Detection and Diagnosis. FAO, Rome.

20. Weisburg, G. W., Barns, S. M., Pelletir, D. A., and Lane, D. J. 1991. 16S ribosomal DNA amplification for phylogenetic study. J. Bacteriol. 173:697-703. 